\title{
A Novel Member of the LDL Receptor Gene Family with Eleven Binding Repeats is Structurally Related to Neural Adhesion Molecules and a Yeast Vacuolar Protein Sorting Receptor
}

\author{
Hiroyuki Yamazaki',2, Hideaki Bujo', and Yasushi Saito' \\ 'Second Department of Internal Medicine, Chiba University School of Medicine, Chiba, Japan. \\ ${ }^{2}$ Medicinal Chemistry Department, Biological Chemistry, Tokyo Research Laboratories, \\ Kowa Co., Ltd., Tokyo, Japan.
}

\begin{abstract}
We now have discovered and characterized a novel multi-domain protein and classified it as a member of the LDL receptor gene family. The $\sim 250 \mathrm{kDa}$ membrane protein, termed LR11, highly conserved in man, rabbit and chicken, contains a cluster of $11 \mathrm{LDL}$ receptor ligand binding repeats, a group of 5 LDL receptor "YWTD" repeats, a large hexarepeat domain of structural elements found in neural cell adhesion molecules, and a domain with similarity to a yeast receptor for vacuolar protein sorting, VPS10. The cytoplasmic domain exhibits features typical of endocytosis-competent coated-pit receptors. The mosaic, and presumably multifunctional, receptor is expressed abundantly in brain, liver and adrenal glands. Ligand blotting of LR11-transfected cells demonstrated that LR11 binds apolipoproteinE-containing lipoproteins, as well as other members of LDL receptor gene family. In contrast to the LDL receptor, the mRNA levels in rabbit liver is unaffected by hyperlipidemia. The features of this highly conserved and complex mosaic protein suggest the importance of the ever expanding LDL receptor gene family in the evolution and proposed multifunctionality. J Atheroscler Thromb, $1997 ; 4: 20-26$.
\end{abstract}

Key words : Gene family, Low density lipoprotein, Adhesion molecule, Vacuolar sorting

In 1984, the primary structure of the low density lipoprotein (LDL) receptor was elucidated by cDNA cloning (1). This was a hallmark in lipoprotein and receptor research and was the molecular basis of familial hypercholesterolemia $(\mathrm{FH})$, one of the most common genetic disease in man (2). As compared with the LDL receptor (LDLR), the physiological roles of newly identified in the past decade and ever expanding LDLR gene family (Fig. 1), are not yet elucidated. These identified common structural modules are (i) the so-called "LDLR ligand binding repeats", complement-type domains consisting of $\sim 40$ residues dis playing a triple-disulfide-bond-stabilized negatively charged

Address for correspondence: Hiroyuki Yamazaki, Second Department of Internal Medicine, Chiba University School of Medicine, 1-8-1 Inohana, Chuo-ku, Chiba 260, Japan.

Received October 10, 1997

This state-of-the-art minireview is based on the article given the 1996 JAS Award of the Distinguished Atherosclerosis Research. surface; (ii) epidermal growth factor precursor-type repeats, also containing six cysteines each ; (iii) modules of $\sim 50$ residues each, most ofter, in groups of five, with a consensus tetrapeptide, Tyr-Trp-Thr-Asp (LDLR "YWTD" repeats); and (iv), in the cytoplasmic region, signals for receptor internalization via coated pits, containing the consensus tetrapeptide Asn-Pro-Xaa-Tyr (NPXY) (3).

The best characterized binding domain is that of the LDLR, which consists of seven complement-type repeats and recognizes apolipoprotein (apo) B and apoE (4). LDLR family members harbor from 1 to 4 clusters with varying numbers of ligand binding repeats. To date, the family includes in addition to the LDLR, the very low density lipoprotein (VLDL) receptor $(5,6)$, Drosophila yolkless $(Y I)(7)$, LDLR related protein $/ \alpha 2$-macroglobulin receptor (LRP) (8), the C. elegans LRP-like gene, (9), gp $330 /$ megalin (10), and the most recent additions, the apoE receptor 2 (11) and brain-specific receptor termed LR8B 


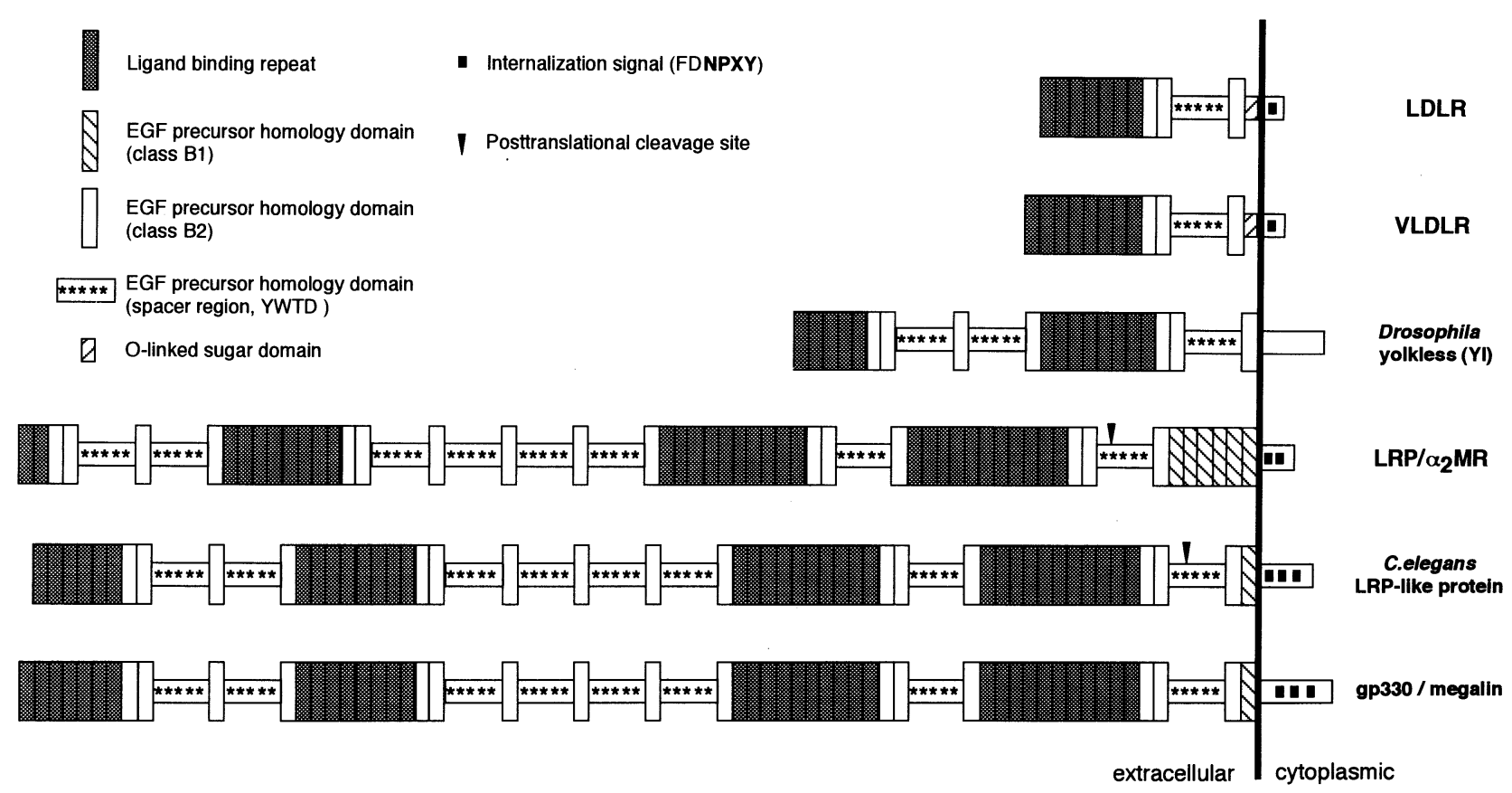

Fig. 1. The LDL receptor gene family. The diagram compares the functional domains in the LDL receptor, VLDL receptor, Drosophila yolkless, LDL receptor-related protein/ $\alpha 2$-macroglobulin receptor $(\mathrm{LRP} / \alpha 2 \mathrm{MR}), \mathrm{C}$. elegans LRP-like protein and gp 330/megalin.

(12). Extensive studies on the ligand specificities of these newly identified proteins have shown that most of them play roles as multifunctional receptors rather than the specific receptors for cellular uptake of plasma lipoproteins. One of the functionally best documented receptor, the VLDL receptor (VLDLR) in chicken oocytes, termed LR8 (13), takes up the yolk precursors, riboflavin binding protein (14), $\alpha 2$-macroglobulin $(\alpha 2 \mathrm{M})(15)$, VLDL, and vitellogenin $(6,16)$. Chicken LR8 also recognizes the iron-binding protein, lactoferrin (17). $\mathrm{YI}$ is a vitellogenin receptor in Drosophila, although its ligand property has not been elucidated (7). LRP and gp $330 /$ megalin have overlapping broad ligand specificities, such as tissue-type plasminogen activator (tPA), urinary-type plasminogen activator, apoE-rich lipoproteins, lactoferrin and lipoprotein lipase. In addition, LRP binds activated $\alpha 2 \mathrm{M}$ and Pseudomonas exotoxin A. Recently, LRP and gp 330/ megalin have been proposed to be the responsible receptors for multifunctional glycoproteins, thrombospondin and apoprotein $\mathrm{J} /$ clusterin, respectively (18-20).

We have recently discovered a novel and unusually complex member of the LDLR gene family in man, rabbit and chicken $(21,22)$, and found that the gene products are highly conserved in such diverse species. The predominant domain of the type I membrane protein consists of a cluster of eleven LDLR ligand binding repeats ; according to our preferred nomenclature (13), the new receptor is termed LR11. It also contains sequences highly homologous to a yeast receptor for vacuolar protein sorting, and to cellular adhesion molecules. Highly expressed in brain, LR11 is proposed to be a member of a hitherto unknown branch of the LDLR gene family which may participate in brain-specific physiological processes.

\section{Identification of a new member of the LDLR gene family, LR11}

cDNA encoding a novel LDLR gene family member, designated LR11 (the LDLR relative with 11 binding repeats) was first identified from a rabbit liver cDNA library using as a probe cDNA encoding the ligand binding domain of the rabbit LDLR(21). Sequencing analysis defined a long open reading frame of $6639 \mathrm{bp}$ which codes for 2213 amino acids. Subsequently, using as a probe rabbit LR11 cDNA clone, human and chicken (partial) LR11 cDNAs were identified from brain cDNA libraries from respective species. (Fig. 2). Despite their considerable size and evolutionary distance, the proteins possess $94 \%$ (man vs. rabbit) and $84 \%$ (man vs. chicken) identical residues, respectively (Figs. 2 and 4). Thus, we now have obtained LR11 cDNAs from three species.

Homology searches of data banks together with a systemic analysis for internal repeats of the predicted amino acid sequence of LR11 demonstrated that the polypeptide has seven distinct domains (Fig. 3) : domain I, $\mathrm{N}$-terminal $\sim 350$ amino acids following the signal sequence ; domain II, a segment related to a yeast receptor for vacuolar protein sorting ; domain III, an EGF precur- 


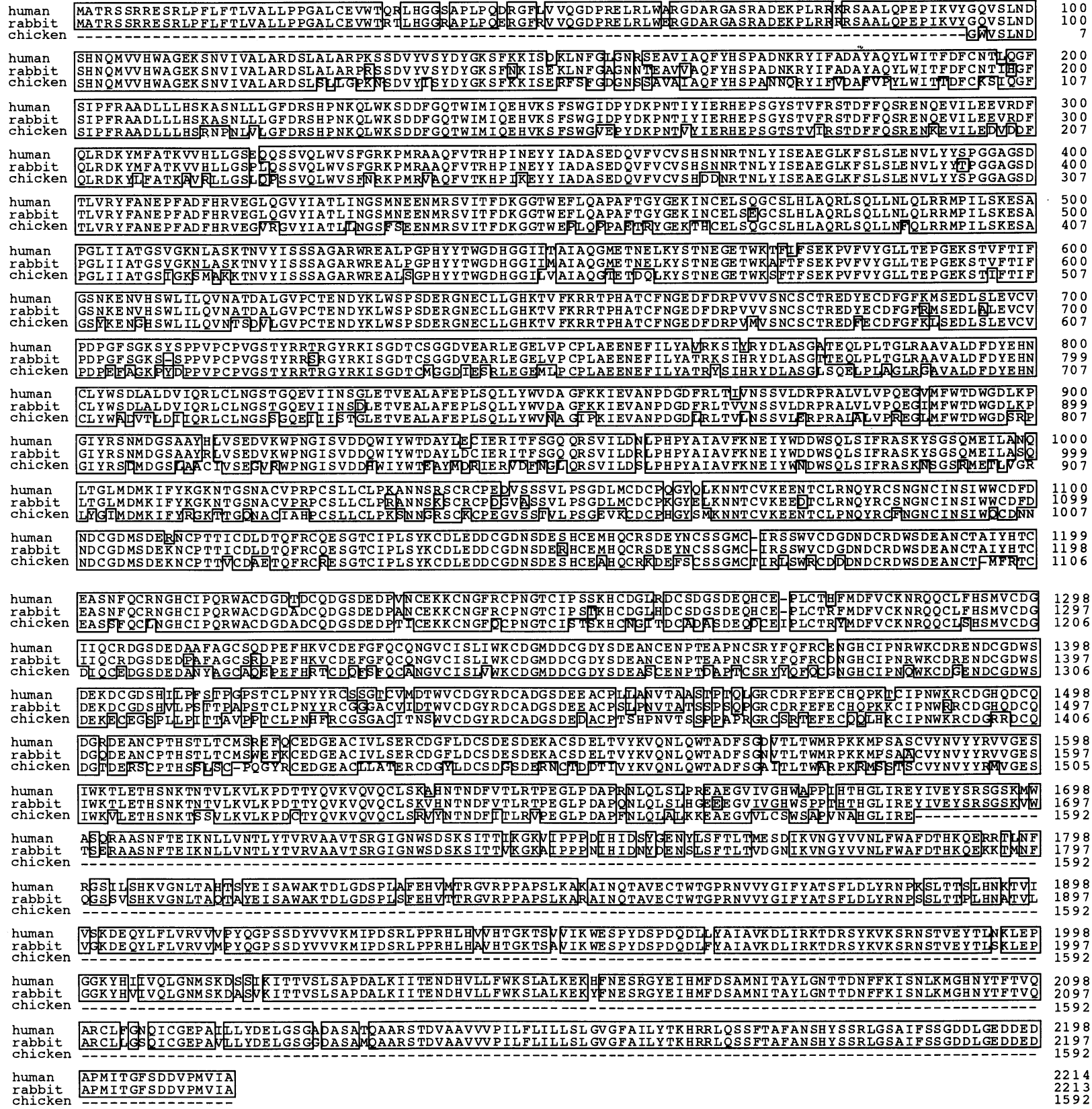

Fig. 2. Comparison of amino acid sequences of human, rabbit and chicken LR11s. The amino acids are numbered from the N-terminus of the human and rabbit LR11 and from the first identified amino acid of chicken LR11, respectively. Gaps (-) have been introduced to optimize the alignment. Identical residues in the three proteins are boxed.

sor homology region; domain IV, a cysteine-rich segment containing 11 copies of the sequence similar to the LDLreceptor ligand binding repeats; domain $\mathrm{V}, 6$ motifs related to the fibronectin type (FN) III repeat; domain $\mathrm{VI}$, a putative membrane spanning region; and domain VII, at the $\mathrm{C}$-terminus 54 amino acids predicted to be a cytoplasmic region.

Domain I is, to our knowledge, the only region of LR11 without significant similarities to other proteins, yet highly conserved in the regions known from all three LR11s (over $80 \%$ identical residues) (Figs. 2 and 4 ).

Domain II shows high homology to a yeast gene, VPS10. The VPS10 has been reported to be a yeast sorting receptor for vacuolar carboxypeptidase $Y(23)$ and a type I transmembrane protein with a large lumenal domain containing two homologous repeats of approximately 650 


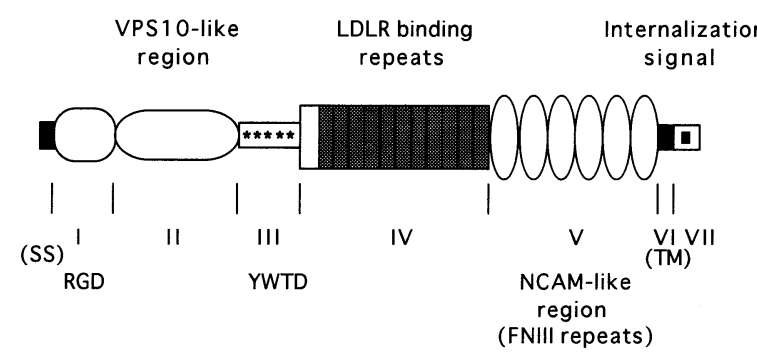

Fig. 3. Schematic diagram of the proposed multidomain structure of the LR11 protein. Seven domains are defined, characterized by: domain I, no particular similarity to other proteins ; domain II, homology to a yeast receptor for vacuolar protein sorting, VPS10; domain III, five repeats with F/YWXD consensus sequences found in the EGF-precursor; domain IV, 11 tandemly arranged complement-type ligand binding repeats highly homologous to those constituting the ligand binding domain of the LDLR; domain V, 6 copies of FNIII repeats; domain $\mathrm{VI}$, a putative membrane spanning region; and domain VII, the cytoplasmic domain. The signal sequence (SS) and the transmembrane domain (TM) are indicated by black boxes.

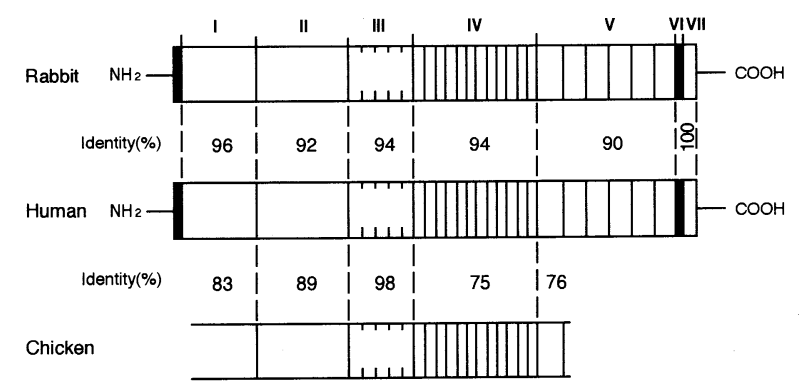

Fig. 4. Amino acid conservation of man, rabbit and chicken LR11s. Seven functional domains (I to VII) in the rabbit and human LR11s are shown. The extents of homology (\% identity) between the domains of rabbit and human LR11s, and of chicken and human LR11s are indicated. Open boxes represent the known portions of domains I and $\mathrm{V}$ of the chicken protein.

amino acids each. The LR11 protein has a single repeat in this domain.

Domain III has the five repeats with characteristic tetrapeptides, F/YWTD. This region, in all three species, is the most highly conserved feature of LR11.

Domain IV is characterized by the 11 tandemly arranged 6-cysteine repeats with remarkable homology to the LDLR ligand binding domain. The LDLR has seven repeats in the binding domain and recognizes apoB and apoE as receptor ligands (2). Other family members have more binding repeats compared to the LDLR: the VLDLR (5), $8 ; \mathrm{YI}(7), 13 ; \operatorname{LRP}(8), 31$; the $C$. elegans LRP-like protein (9), 35; and gp 330/megalin (10), 36. Recent studies on the ligand specificities for these receptors showed a wide range of ligands bind to most family members in vitro in addition to lipoproteins $(17,24-26)$.
The different ligand specificities are most likely to be caused by the different repeated numbers or combinations of the complement-type domains consisting of $\sim 40$ amino acid residues. The eleven binding repeats exist as a cluster in LRP (8), the C. elegans LRP-like protein (9), and gp 330/megalin (10) as well as LR11. These clusters of eleven repeats might be derived from the same ancestral gene because of the popular use in the LDLR gene family members.

Domain $\mathrm{V}$, the $\sim 600$ amino acids strech following the LDLR binding domain homology region is composed of six putative FNIII repeats. The FNIII repeats are shared with several adhesion molecules and a variety of other proteins (27). Part of domain V is most homologous to the FNIII repeat regions in neural cell adhesion molecules.

Domain $\mathrm{VI}$, the putative membrane spanning region is followed by the carboxy terminal domain VII, which are presumed to be a putative cytoplasmic region. In the short cytoplasmic tail, the sequence Phe-Ala-Asn-SerHis-Tyr (FANSHY) is similar to the internalization signal of coated pit receptors $(3,28)$; there are also positively and negatively charged residues near the transmembrane and the C-terminus, respectively, equivalent to those in the similarly short cytoplasmic domains in LDLRs and VLDLRs. Although further studies are needed to determine the role of the consensus motif in LR11, the characteristic signature sequence, together with clusters of charged residues in the cytoplasmic domain also found in other LDLR gene family members, strongly suggest that the LR11 protein is an endocytosis-competent receptor.

Genetic and structural elements defining the LDLR gene family are widespread. Family members identified so far are products of genes that are entirely made up of elements found in the LDLR itself. It is believed that the wide variety of ligands that interact with LDLR family members do so via these complement-type repeats; information on the functional contribution of additional protein domains may be obtained from genes in which LDLR- and non-LDLR-elements are present in novel combinations. We have identified the product of exactly such a gene in man, LR11, which is a striking mosaic protein containing several structural elements so far not found in LDLR gene family members. The elements that put LR11 in the LDLR gene family member, domains III and IV, are located in the center of the molecule, domains VI and VII, are located at the carboxy terminal region of the molecule (Fig. 3).

\section{Chromosomal localization and tissue-specific expression of LR11}

The human LR11 gene locus was mapped to chromosome 11q23.3-24 by fluorescence in situ hybridization (22). The human gene loci of some LDLR gene family members have been identified (Table 1). Each LDLR gene family member is located on the different chromo- 
Table 1

\begin{tabular}{llc}
\hline \multicolumn{1}{c}{ Receptor } & \multicolumn{1}{c}{ Locus } & Reference \\
\hline LDL receptor & 19p13.1-13.3 & 29 \\
VLDL receptor & $9 \mathrm{p} 24$ & 30 \\
LRP & $12 \mathrm{q} 13-14$ & 31 \\
LRP2 (gp330) & 2q24-31 & 32 \\
LR11 & $11 \mathrm{q} 23.3-24$ & 22 \\
\hline
\end{tabular}

some (29-32). The LR11 gene is also on different chromosome from those other members located on.

The rabbit LR11 transcripts are abundantly expressed in brain, liver and adrenal glands by Northern blot analysis. Furthermore, the LR11 transcripts are also present in pancreas, testis, small intestine, lung and thymus, and barely detected in other tissues, such as skeletal muscle, heart, spleen and kidney. In man, the transcripts are mainly observed in brain, liver, kidney, and pancreas (21, 22). LR11 is expressed in brain of all three species; particularly in man, brain is the predominant site of expression.

Immunoblot analysis with anti-LR11 monoclonal antibodies revealed that approximately $250 \mathrm{kDa}$ proteins were present in rabbit brain and liver extracts. These monoclonal antibodies showed no crossreactivity with any other protein in these tissues. Detailed immunoblot analysis of LR11 expression in rabbit brain, using extracts from different portions of brain, showed that the LR11 protein was present predominantly in the cerebrum, but also in the cerebellum and brain stem. Moreover, immunohistochemical analysis to determine the localization of LR11 in rabbit cerebrum revealed the presence of LR11 mainly in the hippocampal CA regions and dentate gyrus, with low level signals in the thalamus, as well as cerebral cortex (21).

\section{Functional analysis of LR11}

ApoE-rich lipoprotein, $\beta$-migrating VLDL $(\beta$-VLDL) is known to be a ligand to all members of the LDLR gene family reported to date $(2,5,33-36)$. Therefore, we examined the binding of $\beta$-VLDL to the LR11-transfected cells by ligand blot analysis (21). A clear signal was obtained in the same position $(\sim 250 \mathrm{kDa})$ as that revealed by immunoblot analysis. These results showed that the LR11 has retained the common binding property of the LDLR gene family.

The expression of the LDLR is tightly regulated by cholesterol (2). To determine the effects of cholesterol on LR11 expression, we analyzed the transcript levels in the liver of a genetically hypercholesterolemic animal, WHHL rabbit (37), by Northern blot analysis. The LR11 expression in the liver of WHHL rabbits was similar to that of normal rabbits (21), clearly indicating that LR11 expression is not affected by cholesterol levels in vivo.

The expression of the LDLR and VLDLR have been known to be stimulated by estrogen (38). We next tested the effects of estrogen on the expression of the LR11 mRNA. For this aim, a chicken estrogen receptor-transfected hepatic cell line, $\mathrm{LMH} / 2 \mathrm{~A}$ cells were used because of the well responsibility to estrogen in vitro (39). PCR amplification indicated that the amount of LR11 transcripts are not changed after the incubation with estrogen. In addition, the LR11 mRNA levels were not affected by the addition of fetal bovine serum(22). These results are rather different from the LDLR, suggesting the LR11 is possibly playing roles in some other function in addition to lipoprotein metabolism.

The most characteristic structural module of the LDLR gene family, LDLR ligand binding repeats are also found in a wide variety of proteins whose functions seem to be unrelated to lipoprotein metabolism. Among these are several proteins of the blood complement system $(40,41)$; a basement membrane heparan sulfate proteoglycan, perlecan $(42,43)$; a rat apical early endosomal glycoprotein (44); a cortical granule protein in sea urchin (45); a linker chain of earthworm hemoglobin (46); a G-protein coupled receptor in the ganglion of Lymnaea (47); and a chicken rous sarcoma virus receptor (48). Thus, the complement-type repeats in the LDLR are shared by a number of proteins that participate in diverse biological processes. For instance, the occurrence of complement-type repeats together with EGF precursor homology domain(s) in some extracellular matrix proteins, such as perlecan, suggests that certain family members might be involved in cell growth and cellular attachment.

\section{Conclusions}

Receptors belonging to the LDLR gene family are playing key roles for wide varied species in cellular endocytosis of a broad spectrum of ligands including spent, biologically inactive and/or unwanted plasmatic carrier complexes, certain toxins, yolk precursors, as well as circulating plasma lipoproteins. Recently, Kounnas et al. reported that LRP binds, in addition to many other possible ligands, $\beta$-amyloid precursor protein and mediates its degradation in vitro (49). At present, we have no idea which ligand(s) may be the true physiological partner(s) of LR11. The localization of rabbit LR11 in the hippocampus, dentate gyrus and cerebral cortex suggests functional significance of LR11 in metabolically active regions of brain. For instance, glutamate receptors, thought to play key roles in active brain functions such as learning (50), are highly expressed in the same brain structures (51).

Here we described a novel member of the LDLR gene family discovered in man, rabbit, and chicken. The LR11, as well as the recently identified apoE receptor 2 (11) and LR8B (12) appear to define a new group of LDLR family members with possible brain-specific functions (52). The novel complex mosaic structure of LR11 sheds new 
lights on the evolution and proposed multifunctionality of the LDLR gene family.

Acknowledgements: These studies were carried out in collaboration with Dr. W.J. Schneider (University of Vienna), and we would like to thank Drs. H. Hashimoto (Daiichi Pure Chemicals Co., Ltd.), A. Iwasaki, M. Nakamura, H. Tani (Kowa Co., Ltd.), I. Ishii (Faculty of Pharmaceutical Science, Chiba University), K. Tanaka, M. Otabe, T. Kanaki, K. Seimiya, J. Kusunoki, and N. Morisaki (Chiba University School of Medicine) for their great contributions.

\section{References}

(1) Yamamoto T, Davis CG, Brown MS, Schneider WJ, Casey $\mathrm{ML}$, Goldstein JL, and Russell DW: The human LDL receptor: a cysteine-rich protein with multiple Alu sequences in its mRNA. Cell, 39: 27-38, 1984

(2) Brown MS and Goldstein JL: A receptor-mediated pathway for cholesterol homeostasis. Science, 232 : 34-47, 1986

(3) Chen WJ, Goldstein JL, and Brown MS: NPXY, a sequence often found in cytoplasmic tails, is required for coated pit-mediated internalization of the low density lipoprotein receptor. J Biol Chem, 265 : 3116-3123, 1990

(4) Russell DW, Brown MS, and Goldstein JL: Different combinations of cysteine-rich repeats mediate binding of low density lipoprotein receptor to two different proteins. J Biol Chem, $264:$ 21682-21688, 1989

(5) Takahashi S, Kawarabayasi Y, Nakai T, Sakai J, and Yamamoto $\mathrm{T}$ : Rabbit very low density lipoprotein receptor: A low density lipoprotein receptor-like protein with distinct ligand specificity. Proc Natl Acad Sci USA, 89 : 9252-9256, 1992

(6) Bujo H, Hermann M, Kaderli MO, Jacobsen L, Sugawara $\mathrm{S}$, Nimpf J, Yamamoto T, and Schneider WJ : Chicken oocyte growth is mediated by an eight ligand binding repeat member of the LDLR family. EMBO J, 13: 51655175,1994

(7) Schonbaum CP, Lee S, and Mahowald AP: The Drosophila yolkless gene encodes a vitellogenin receptor belonging to the low density lipoprotein receptor superfamily. Proc Natl Acad Sci USA, 92 : 1485-1489, 1995

(8) Herz J, Hamann U, Rogne S, Myklebost O, Gausepohl H, and Stanley KK: Surface location and high affinity for calcium of a 500-kd liver membrane protein closely related to the LDL-receptor suggest a physiological role as lipoprotein receptor. EMBO J, $7: 4119-4127,1988$

(9) Yochem J and Greenwald I: A gene for a low density lipoprotein receptor-related protein in the nematode Caenorhabditis elegans. Proc Natl Acad Sci USA, 90 : 4572-4576, 1993

(10) Saito A, Pietromonaco S, Loo AKC, and Farquhar MG : Complete cloning and sequencing of rat gp 330/ "megalin," a distinctive member of the low density lipoprotein receptor gene family. Proc Natl Acad Sci USA 91: 9725-9729, 1994

(11) Kim DH, lijima H, Goto K, Sakai J, Ishii H, Kim HJ, Suzuki $\mathrm{H}$, Kondo $\mathrm{H}$, Saeki S, and Yamamoto $\mathrm{T}$ : Human apolipoprotein $\mathrm{E}$ receptor 2. A novel lipoprotein receptor of the low density lipoprotein receptor family predominantly expressed in brain. J Biol Chem, 271: 1-8, 1996

(12) Novak S, Hiesberger T, Schneider WJ, and Nimpf J: A new LDL receptor homologue with 8 ligand binding repeats in brain of chicken and mouse. J Biol Chem, 271: 11732-11736, 1996

(13) Bujo H, Lindstedt KA, Hermann M, Dalmau LM, Nimpf J, and Schneider WJ : Chicken oocytes and somatic cells express different splice variants of a multifunctional receptor. J Biol Chem, 270: 23546-23551, 1995

(14) Mac Lachlan I, Nimpf J, and Schneider WJ : Avian riboflavin binding protein binds to lipoprotein receptors in association with vitellogenin. J Biol Chem, 269: 24127-24132, 1994

(15) Jacobsen L, Hermann M, Vieira PM, Schneider WJ, and Nimpf $\mathrm{J}$ : The chicken oocyte receptor for lipoprotein deposition recognizes $\alpha 2$-macroglobulin. J Biol Chem, 270 : 6468-6475, 1995

(16) Bujo H, Yamamoto T, Hayashi K, Hermann M, Nimpf J, and Schneider WJ: Mutant oocytic low density lipoprotein receptor gene family member causes atherosclerosis and female sterility. Proc Natl Acad Sci USA, 92 : 9905-9909, 1995

(17) Hiesberger T, Hermann M, Jacobsen L, Novak S, Hodits RA, Bujo $H$, Meilinger $M$, Hüttinger $M$, Schneider WJ, and Nimpf J: The chicken oocyte receptor for yolk precursors as a model for studying the action of receptorassoiated protein and lactoferrin. J Biol Chem, 270: 18219-18226, 1995

(18) Godyna S, Liau G, Popa I, Stefansson S, and Argraves WS: Identification of the low density lipoprotein receptor-related protein (LRP) as an endocytic receptor for thrombospondin-1. J Biol Chem, 129: 1403-1410, 1995

(19) Kounnas MZ, Loukinova EB, Stefansson S, Harmony JAK, Brewer BH, Argraves SDK, and Argraves WS : Identification of glycoprotein 330 as an endocytic receptor for apolipoprotein J/clusterin. J Biol Chem, 270: 1307013075, 1995

(20) Mikhailenko I, Kounnas M, and Strickland DK: Low density lipoprotein receptor-related protein $/ \alpha 2$-macroglobulin receptor mediates the cellular internalization and degradation of thrombospondin. J Biol Chem, 270 : 9543-9549, 1995

(21) Yamazaki H, Bujo H, Kusunoki J, Seimiya K, Kanaki T, Morisaki N, Schneider WJ, and Saito Y: Elements of neural adhesion molecules and a yeast vacuolar protein sorting receptor are present in a novel mammalian low density lipoprotein receptor family member. J Biol Chem, 271: 24761-24768, 1996

(22) Mörwald S, Yamazaki H, Bujo H, Kusunoki J, Kanaki T, Seimiya K, Morisaki N, Nimpf J, Schneider WJ, and Saito $Y$ : A novel mosaic protein containing $L D L$ receptor elements is highly conserved in man and chicken. Arterioscler Thromb Vascular Biol, 17 : 996-1002, 1997

(23) Marcusson EG, Horazdovsky BF, Cereghino JL, Gharakhanian E, and Emr SD: The sorting receptor for yeast vacuolar carboxypeptidase $\mathrm{Y}$ is encoded by the VPS10 gene. Cell, $77: 579-586,1994$

(24) Krieger $M$ and Herz $\mathrm{J}$ : Structures and functions of multiligand lipoprotein receptors : macrophage scavenger receptors and LDLR-related protein (LRP). Annu Rev Biochem, 63: 601-637, 1994

(25) Moestrup SK: The $\alpha 2$-macroglobulin receptor and epithelial glycoprotein-330 : two giant receptors mediat- 
ing endocytosis of multiple ligands. Biochim Biophys Acta, 1197: 197-213, 1994

(26) Bujo $\mathrm{H}$ and Yamamoto $\mathrm{T}$ : VLDL receptor in health and disease : interview with a receptor in avian oocytes and mammalian muscle and fat cells. J Atheroscler Thromb, 2: 71-75, 1996

(27) Patthy L: Homology of a domain of the growth hormone/ prolactin receptor family with type III modules of fibronectin. Cell, 61: 13-14, 1990

(28) Naim HY and Roth MG : Characteristics of the internalization signal in the Y543 influenza virus hemagglutinin suggest a model for recognition of internalization signals containinig tyrosine. J Biol Chem, 269: 3928-3933, 1994

(29) Lindgren V, Luskey KL, Russell DW, and Francke U : Human genes involved in cholesterol metabolism: Chromosomal mapping of the loci for the low density lipoprotein receptor and 3-hydroxy-3-methylglutarylcoenzyme $A$ reductase with cDNA probes. Proc Natl Acad Sci USA, 82 : 8567-8571, 1985

(30) Oka K, Tzung KW, Sullivan M, Lindsay E, Baldini A, and Chan $L$ : Human very low density lipoprotein receptor complementary DNA and deduced amino acid sequence and localization of its gene (VLDLR) to chromosome band 9 p24 by fluorescence in situ hybridization. Genomics, 20: 298-300, 1994

(31) Hilliker C, Van Leuven $F$, and Van den Berghe $H$ : Assignment of the gene coding for the alpha 2-macroglobulin receptor to mouse chromosome 15 and to human chromosome 12q13-q14 by isotopic and nonisotopic in situ hybridization. Genomics, 13: 472-474, 1992

(32) Korenberg JR, Argraves KM, Chen XN, Tran $\mathrm{H}$, Strickland DK, and Argraves WS: Chromosomal localization of human genes for the LDL receptor family member glycoprotein 330 (LRP2) and its associated protein RAP (LRPAP1). Genomics, 22 : 88-93, 1994

(33) Beisiegel U, Weber W, Ihrke G, Herz J, and Stanley KK: The LDL-receptor-related protein, LRP, is an apolipoprotein E-binding protein. Nature, 341: 162-164, 1989

(34) Kowal RC, Herz J, Goldstein JL, Esser V, and Brown MS : Low density lipoprotein receptor-related protein mediates uptake of cholesterol esters derived from apoprotein E-enriched lipoproteins. Proc Natl Acad Sci USA, 86 : 5810-5814, 1989

(35) Hussain MM, Maxfield FR, Mas-Oliva J, Tabas I, Ji ZS, Innerarity TL, and Mahley RW: Clearance of chylomicron remnants by the low density lipoprotein receptorrelated protein $/ \alpha 2$-macroglobulin receptor. J Biol Chem, 226 : 13936-13940, 1991

(36) Willnow TE, Goldstein JL, Orth K, Brown MS, and Herz J : Low density lipoprotein receptor-related protein and gp 330 bind similar ligands, including plasminogen activator-inhibitor complexes and lactoferrin, an inhibitor of chylomicron remnant clearance. J Biol Chem, 267 : 26172-26180, 1992

(37) Yamamoto T, Bishop RW, Brown MS, Goldstein JL, and Russell DW: Deletion in cysteine-rich region of LDLR impedes transport to cell surface in WHHL rabbit. Science, 232: 1230-1237, 1986

(38) Masuzaki $H$, Jingami $H$, Yamamoto $T$, and Nakao K : Effect of estradiol on very low density lipoprotein receptor mRNA levels in rabbit heart. FEBS Lett, $347: 211-214$, 1994
(39) Berkowitz EA, Chu WW, and Evans MI: Insulin inhibits the estrogen-dependent expression of the chicken very low density apolipoprotein II gene in leghorn male hepatoma cells. Mol Endocrinol, 7 : 507-514, 1986

(40) Haefliger JA, Tschopp J, Nardelli D, Wahli W, Kocher HP, Tosi M, and Stanley KK : Complementary DNA cloning of complement $\mathrm{C} 8 \mathrm{~b}$ and its sequence homology to $\mathrm{C}$. Biochemistry, 26 : 3551-3556, 1987

(41) Hobbs HH, Russell DW, Brown MS, and Goldstein JL: The LDLR locus in familial hypercholesterolemia: mutational analysis of a membrane protein. Annu Rev Genet, 24 : 133-170, 1990

(42) Noonan DM, Fulle A, Valente P, Cai S, Horigan E, Sasaki $M$, Yamada $Y$, and Hassell JR: The complete sequence of perlecan, a basement membrane heparan sulfate proteoglycan, reveals extensive similarity with laminin A chain, low density lipoprotein-receptor, and the neural cell adhesion molecule. J Biol Chem, 266: 2293922947, 1991

(43) Kallunki P and Tryggvason K : Human basement membrane heparan sulfate proteoglycan core protein : a $467-$ $\mathrm{kD}$ protein containing multiple domains resembling elements of the low density lipoprotein receptor, laminin, neural cell adhesion molecules, and epidermal growth factor. J Cell Biol, 116 : 559-571, 1992

(44) Speelman BA, Allen K, Grounds TL, Neutra MR, Kirchhausen $\mathrm{T}$, and Wilson $\mathrm{JM}$ : Molecular characterization of an apical early endosomal glycoprotein from developing rat intestinal epithelial cells. J Biol Chem, 270: 15831588, 1995

(45) Wessel GM : A protein of the sea urchin cortical granules is targeted to the fertilization envelope and contains an LDL-receptor-like motif. Dev Biol, 167: 388-397, 1995

(46) Suzuki T and Riggs AF : Linker chain L1 of Earthworm hemoglobin. Structure of gene and protein: Homology with low density lipoprotein receptor. J Biol Chem, 268 : 13548-13555, 1993

(47) Tensen CP, van Kesteren ER, Planta RJ, Cox KJA, Burke $\mathrm{JF}$, van Heerikhuizen $\mathrm{H}$, and Vreugdenhil $\mathrm{E}$ : A G proteincoupled receptor with low density lipoprotein-binding motifs suggests a role for lipoproteins in G-linked signal transduction. Proc Natl Acad Sci USA, 91: 4816-4820, 1994

(48) Bates P, Young JAT, and Varmus HE: A receptor for subgroup A rous sarcoma virus is related to the low density lipoprotein receptor. Cell, 74 : 1043-1051, 1993

(49) Kounnas MZ, Moir RD, Rebeck GW, Bush Al, Argraves WS, Tanzi RE, Hyman BT, and Strickland DK: LDLRrelated protein, a multifunctional apo $E$ receptor, binds secreted $\beta$-amyloid precursor protein and mediates its degradation. Cell, 82: 331-340, 1995

(50) Bliss TVP and Collingridge GL: A synaptic model of memory: long-term potentiation in the hippocampus. Nature, 361: 31-39, 1993

(51) Meguro $H$, Mori $H$, Araki K, Kushiya E, Kutsuwada T, Yamazaki M, Kumanishi T, Arakawa M, Sakimura K, and Mishina $M$ : Functional characterization of a heteromeric NMDA receptor channel expressed from cloned cDNAs. Nature, $357:$ 70-74, 1992

(52) Yamamoto $\mathrm{T}$ and Bujo $\mathrm{H}$ : Close encounters to apoprotein E receptors. Curr Opin Lipidol, $7: 298-302$, 1996 